\title{
Безопасность комбинированной терапии сальметеролом и флутиказона пропионатом у больных бронхиальной астмой
}

Санкт-Петербургская медицинская академия последипломного образования: 193015, Санкт-Петербург, ул. Кирочная, 41

\section{A.V.Emelyanov, G.R.Sergeeva \\ Safety of combines therapy with salmeterol and fluticasone propionate in patients with bronchial asthma}

Key words: salmeterol, fluticasone, safety, asthma.

Ключевые слова: салметерол, флутиказон, безопасность, астма.

Комбинированная терапия ингаляционными глюкокортикостероидами (иГКС) и $\beta_{2}$-адреномиметиками длительного действия - ДДБА (сальметеролом и формотеролом) играет важную роль при лечении больных бронхиальной астмой (БА), что нашло отражение в международных согласительных документах [1]. Добавление формотерола или сальметерола улучшает контроль над течением БА эффективнее, чем увеличение дозы иГКС у пациентов с недостаточным эффектом при использовании низких доз этих препаратов [2, 3].

Результаты проведенных клинических исследований явились основанием для создания и использования в клинической практике фиксированных комбинаций иГКС и ДДБА, которые являются высокоэффективными средствами для лечения БА и хронической обструктивной болезни легких. Данная статья посвящена изучению безопасности применения комбинации сальметерола / флутиказона пропионата (Серетида) у больных БА.

\section{Безопасность сальметерола}

Дискуссия о безопасности ДДБА инициирована результатами 2 исследований. Одно из них (Serevent Nationwide Surveillance Study) выполнено в Великобритании. В него были включены 25000 больных БА, которые получали сальметерол 2 раза в день или сальбутамол 4 раза в день в течение 16 нед. на фоне предшествующей противоастматической терапии. Общее число обострений БА в группе пациентов, получавших сальметерол, снижалось, однако у больных отмечалось недостоверное увеличение числа летальных исходов, связанных с БА (12 из 16 787, по сравнению с 2 из 8393 больных, принимавших сальбутамол; $p=0,105)$. Причем у всех 14 умерших была диагностирована тяжелая БА. При анализе полученных результатов следует иметь в виду, что лишь $31 \%$ больных в обеих группах получали иГКС, и при этом не изучалась приверженность пациентов к их приемy [4].
Другое исследование (Salmeterol Multicenter Asthma Research Trial-SMART) проводилось в 6136 центрах США и включало в себя 26355 пациентов с БА в возрасте $\geq 12$ лет [5]. Примерно половина больных получали сальметерол в дозе 42 мкг в сутки (2 раза в день), остальные - плацебо в течение 28 нед. Дополнительно пациентам назначалось обычное лечение астмы, причем лишь 47 \% получали иГКС. $73 \%$ участников завершили исследование. В группе пациентов, получавших сальметерол, отмечалось небольшое, но статистически достоверное увеличение случаев смерти от респираторных причин, числа летальных исходов от БА и угрожающих жизни состояний, связанных с астмой. Риск их развития был наибольшим в группе афроамериканцев и больных, не получавших иГКС.

В обоих исследованиях число кардиоваскулярных побочных эффектов было одинаковым в группах, получавших сальметрол и плацебо.

При анализе полученных данных закономерно возникает вопрос: существует ли у части пациентов достаточно редкая повышенная чувствительность к побочным эффектам ДДБА или повышение смертности является результатом монотерапии сальметеролом, которая контролировала симптомы заболевания и при этом маскировала воспаление дыхательных путей?

Для поиска ответа на первую часть вопроса были проанализированы различные фенотипы и генотипы больных БА. Как известно, у афроамериканцев, имеющих наибольший риск фатальных и угрожающих жизни обострений, чаще встречается генетический полиморфизм $\beta_{2}$-адренорецепторов, по сравнению с людьми белой расы. В связи с этим возникло предположение о том, что генетические различия в строении $\beta_{2}$-рецепторов могут объяснить результаты исследования SMART.

Установлено, что $\beta_{2}$-адренорецепторы принадлежат к семейству связанных с G-протеинами белков клеточных мембран и содержат 413 аминокислот [6]. 
Ген, кодирующий их синтез, локализован на длинном плече 5-й хромосомы. Выявлено несколько нуклеотидных полиморфизмов, заключающихся в замене аминокислот (глютамина, аргинина и др.) в 16, 27 и 164-м кодонах.

Большинство проведенных исследований показывают, что влияние генотипа $\beta_{2}$-рецептора имеет значение только для $\beta_{2}$-агонистов короткого действия [7]. В 2 больших рандомизированных исследованиях, включавших в себя 2250 (833 Gly / Gly, 1028 Gly / Arg, 361 Arg / Arg) и 405 (168 Gly / Gly, 169 Gly / Arg, 67 Arg / Arg) пациентов с БА, установлено, что полиморфизм $\beta_{2}$-рецепторов не влияет на ответ больных БА на ДДБА при лечении комбинацией формотерола и будесонида [8]. В исследовании 183 больных БА (65 Gly / Gly, 89 Gly / Arg, 29 Arg / Arg), получавших комбинированную терапию сальметеролом и флютиказона пропионатом, также не было выявлено различий по ответу на сальметерол в зависимости от генотипа $\beta_{2}$-рецепторов [9].

Таким образом, пациенты с БА, независимо от имеющегося генотипа, могут продолжать прием иГКС и ДДБА.

Наиболее вероятным объяснением полученных результатов представляется предположение о том, что монотерапия сальметеролом, уменьшая выраженность симптомов БА за счет бронходилатации, может маскировать воспаление дыхательных путей. Это подтверждается опубликованным недавно метаанализом, в котором показано отсутствие у ДДБА значимого противовоспалительного или провоспалительного действия. Клинические эффекты препаратов, вероятно, обусловлены их длительным бронхорасширяющим действием [10]. Так, в полости носа, где нет гладкомышечных клеток, не наблюдалось синергичного эффекта от приема ДДБА и иГКС [11]. В группе афроамериканцев, принимавших участие в исследовании SMART [5], отмечалось исходно более тяжелое течение БА и меньшая частота приема иГКС. Если пациенты-афроамериканцы использовали иГКС, терапия сальметеролом так же, как и у представителей европеоидной расы, не увеличивала риск неблагоприятных исходов по сравнению с приемом плацебо.

Полученные результаты явились причиной предостережения Food and Drug Administration (FDA, США) о том, что ДДБА при лечении астмы можно использовать только вместе с иГКС. Следует подчеркнуть, что данное положение касается как сальметерола, так и формотерола.

\section{Безопасность флутиказона пропионата}

Флутиказона пропионат обладает наиболее выраженной среди всех иГКС противовоспалительной активностью. Его системная биодоступность при приеме per os составляет < 1 \%, при ингаляциях 10-30 \% (в зависимости от типа устройства доставки: наименьшая отмечается при использовании мультидиска, более высокая - при использовании дозированных аэрозольных ингаляторов). Эффект 1-го прохождения через печень высок ( 99 \%) [12].
Эквивалентные терапевтические дозы флутиказона пропионата почти в 2 раза меньше, чем у беклометазона дипропионата [1].

Терапия любыми иГКС способна вызывать местные побочные эффекты, к которым относятся кандидоз полости рта и пищевода, дисфония и кашель. Лечение некоторых пациентов требует применения средних и высоких доз иГКС, которые могут попадать в системный кровоток через легкие и желудочнокишечный тракт и приводить к развитию системных побочных эффектов вследствие фармакологических взаимодействий с гипоталамо-гипофизарной осью.

Местные побочные эффекты свойственны всем известным иГКС. Они зависят от дозы препарата и вида дозирующего устройства.

Флутиказона пропионат, будесонид и беклометазона дипропионат в равной степени способны вызывать кандидоз полости рта [13]. Для флутиказона пропионата частота развития кандидоза являлась дозозависимой и при высоких суточных дозах (880 мкг в сутки) достигала $5,2 \%$.

Считалось, что кандидоз пищевода вследствие применения иГКС встречается достаточно редко, однако при использовании эндоскопических методов исследования частота этого побочного эффекта может достигать 35-37 \% [14]. Для флутиказона пропионата частота развития кандидоза пищевода также является дозозависимой. Было показано, что сразу после ингаляции 200 мкг флутиказона пропионата в пищеводе обнаруживается значительное количество (3,3 мкг) препарата и, если пациент ложился спать, то через 30 мин оно сохраняется на уровне 0,67 мкг, а если остается в вертикальном положении - 0,11 мкг. Соответственно пациентам рекомендуется не ложиться сразу после ингаляции ФП, а также применять препарат до завтрака и ужина, чтобы его частицы удалялись из пищевода с пассажем пищи [15].

Сходная частота местных побочных эффектов наблюдалась и при использовании комбинации ДДБА / иГКС. В частности, комбинация сальметерол / флутиказона пропионат вызывала кандидоз полости рта в 2-4 \%, дисфонию / осиплость голоса в 2-4 \% и кашель - в 1-3\% случаев [16].

Проникновение иГКС в системный кровоток происходит либо через легкие, либо путем проглатывания части препарата, осевшего на задней стенке глотки. Проникновение через желудочно-кишечный тракт вносит минимальный вклад в системное действие иГКС, по сравнению со всасыванием через легкие, поскольку проглоченный и всосавшийся в кишечнике иГКС подвергается печеночному метаболизму, что значительно сокращает количество циркулирующего препарата. В случае флутиказона пропионата и мометазона фуроата при 1-м прохождении через печень нейтрализуется 99 \% препарата, для будесонида этот показатель составляет $90 \%$, для триамцинолона ацетонида - 80-90 \%, для беклометазона дипропионата - 60-70\% [17].

Большая часть системного действия иГКС обусловлена прямым всасыванием из нижних дыхатель- 
ных путей, когда препарат не подвергается печеночному метаболизму.

Большое значение приобретает способность связываться с белками плазмы, и чем выше эта способность, тем ниже риск развития системных побочных эффектов, так как биологически активной является только свободная фракция препарата. Степень связывания с белками плазмы для триамцинолона ацетонида составляет $71 \%$, для будесонида $-88 \%$, для флутиказона пропионата - 90 \%. Для беклометазона дипропионата этот показатель равен $87 \%$, но нет данных для его активного метаболита - беклометазона монопропионата [12].

Важным параметром фармакокинетики является также липофильность, обеспечивающая увеличение аффинности и длительности связывания препарата с глюкокортикоидным рецептором. По липофильности флутиказона пропионата в 3 раза превосходит беклометазона пропионат и в 300 раз - будесонид [24]. Несмотря на то, что флутиказона пропионат значительно превосходит по своей активности беклометазон и будесонид, риск местных и системных побочных эффектов при его использовании не превышает, а в некоторых наблюдениях он ниже, чем при использовании эквипотентных доз других иГКС. Например, метаанализ 7 многоцентровых исследований показал, что при среднетяжелой и тяжелой БА флутиказона пропионат обладает более благоприятным соотношением эффективность / системные эффекты (терапевтическим индексом), чем будесонид и беклометазона дипропионат [25].

Сведения о системных эффектах иГКС суммированы в табл. 1.

Меры профилактики местных и системных побочных эффектов приведены в табл. 2.

\section{Системные побочные эффекты иГКС [14]}

\begin{tabular}{|c|c|c|}
\hline $\begin{array}{l}\text { Точка } \\
\text { приложения }\end{array}$ & $\begin{array}{c}\text { Степень } \\
\text { доказательности }\end{array}$ & Заключение \\
\hline Минеральная & A & Применение иГКС не связано со снижением минеральной плотности костей у детей с БА \\
\hline плотность костей & C & $\begin{array}{l}\text { Обычно у взрослых пациентов с БА не отмечается существенного снижения минеральной плотности костей, } \\
\text { но в случае многолетнего применения высоких доз иГКС их влияние может стать клинически значимым }\end{array}$ \\
\hline \multirow[t]{3}{*}{ Катаракта } & C & $\begin{array}{l}\text { Риск возникновения субкапсулярной или нуклеарной катаракты при использовании иГКС у молодых } \\
\text { незначителен, но может повышаться у пациентов старшего возраста }\end{array}$ \\
\hline & & - Данных о сравнительном риске возникновения катаракты при использовании разных иГКС недостаточно \\
\hline & & · Соотношение доза-эффект между использованием иГКС и возникновением катаракты не определено \\
\hline \multirow[t]{3}{*}{ Глаукома } & & $\begin{array}{l}\text { · Риск возникновения глаукомы, связанной с применением иГКС, представляется небольшим и требует } \\
\text { дальнейших исследований }\end{array}$ \\
\hline & & · Данных о сравнительном риске возникновения глаукомы при использовании разных иГКС недостаточно \\
\hline & & $\begin{array}{l}\text { - Предполагается, хотя пока недостаточно изучено, наличие дозозависимого эффекта между применением } \\
\text { иГКС и возникновением глаукомы }\end{array}$ \\
\hline \multirow[t]{3}{*}{ Рост } & A & $\begin{array}{l}\text { Терапия иГКС связана с краткосрочным замедлением роста у детей, но выраженность этого эффекта мала } \\
\text { и нивелируется при длительном лечении }\end{array}$ \\
\hline & C & $\begin{array}{l}\text { Рост взрослых людей, которые в детстве получали иГКС для лечения БА, не отличается от роста людей, } \\
\text { не страдающих астмой }\end{array}$ \\
\hline & C & Недостаточно данных, чтобы сделать выводы о сравнительном влияния на рост разных препаратов иГКС \\
\hline \multirow[t]{3}{*}{ Кожа } & B & $\begin{array}{l}\text { У пациентов, получающих иГКС, риск истончения кожи и ее легкой ранимости повышен. На уровень риска } \\
\text { большое влияние оказывают доза, длительность применения иГКС и пол пациента }\end{array}$ \\
\hline & & · Данных о сравнительном риске истончения и ранимости кожи при использовании разных иГКС недостаточно \\
\hline & B & Предполагается наличие дозозависимого эффекта между применением иГКС и истончением / ранимостью кожи \\
\hline
\end{tabular}

Примечание: доказательство А - имеется достаточно данных для оценки связи между препаратом и осложнением (заключение основано на результатах, по крайней мере, 2 хорошо выполненных рандомизированных слепых клинических исследований); доказательство В - имеется достаточно данных для оценки связи между препаратом и осложнением (заключение основано на результатах > 1 хорошо выполненного обсервационного исследования, но не подтверждено проспективными, рандомизированными клиническими исследованиями); доказательство C - имеется достаточно данных для оценки связи между препаратом и осложнением (заключение основано на большом числе доказательств, однако имеются противоречивые сведения, что требует осторожности в интерпретации данных).

Таблица 2

Меры профилактики побочных эффектов

\begin{tabular}{|c|c|}
\hline Эффекты & Меры профилактики \\
\hline \multicolumn{2}{|c|}{ Местные побочные эффекты: } \\
\hline Кандидоз полости рта & $\begin{array}{l}\text { Использование спейсера или порошковых ингаляторов, полоскание полости рта водой после ингаляции, } \\
\text { менее частое использование препарата (2-кратный, а не 4-кратный прием в течение дня). В случае активной } \\
\text { инфекции показано применение местных или системных антифунгальных препаратов }\end{array}$ \\
\hline Дисфония & $\begin{array}{l}\text { Использование спейсера или порошковых ингаляторов, менее частое использование препарата, рекомендуется } \\
\text { щадить голос }\end{array}$ \\
\hline $\begin{array}{l}\text { Рефлекторный кашель } \\
\text { и бронхоспазм }\end{array}$ & Более медленный вдох, использование спейсера, предварительная ингаляция $\beta_{2}$-агониста \\
\hline $\begin{array}{l}\text { Системные побочные } \\
\text { эффекты }\end{array}$ & $\begin{array}{l}\text { Использование спейсера, порошковых ингаляторов и полоскание полости рта после ингаляции;применение } \\
\text { минимально возможной дозы иГКС для контроля БА; добавление к терапии других классов лекарственных } \\
\text { препаратов (ДДБА) перед увеличением дозы иГКС }\end{array}$ \\
\hline
\end{tabular}


Меры профилактики местных и системных побочных эффектов аналогичны при применении различных лекарственных препаратов группы иГКС.

Следует подчеркнуть, что риск развития системных побочных эффектов при использовании высоких доз иГКС значительно ниже, чем при применении системных глюкокортикоидов.

\section{Безопасность фиксированной комбинации сальметерола / флутиказона пропионата}

Комбинированный препарат, содержащий в 1 ингаляции сальметерол и флутиказона пропионат (Серетид) используется в клинической практике с 1998 г. и является высокоэффективным средством для лечения БА. Добавление сальметерола к флутиказона пропионату обеспечивает стероидосберегающий эффект, при этом снижение дозы флутиказона пропионата не ухудшает контроль над астмой (выраженность симптомов, легочная функция и потребность в $\beta_{2}$-агонистах короткого действия) и не увеличивает число обострений, тогда как снижение дозы иГКС, применяемых в режиме монотерапии, приводит к ухудшению течения заболевания [18]. Показано, что использование флутиказона пропионата / сальметерола в течение 1 года позволяет добиться полного контроля над БА у большего числа больных, чем при использовании монотерапии флутиказона пропионатом. Комбинированная терапия позволяла достичь более быстрого эффекта при использовании низких доз флутиказона пропионата [3]. Сходные результаты были получены и в популяции афро-американцев [19]. Во всех исследованиях показана хорошая переносимость препарата, что подтверждено несколькими опубликованными метаанализами [2023]. На заседании комитета FDA от 10-11 декабря 2008 г. было решено, что в настоящее время получено достаточно данных об эффективности и безопасности у взрослых и детей комбинированного препарата Advair, зарегистрированного в Российской Федерации под названием "Серетид". Польза от его применения превосходит риск развития возможных побочных эффектов, а имеющиеся данные позволяют рекомендовать препарат для широкого клинического применения у пациентов с БА.

Статья опубликована при финансовой поддержке компании "ГлаксоСмитКляйн"

\section{Литература}

1. Global initiative for asthma. NHLB / WHO Workshop Report. National Heart Lung Blood Institute, Publication number 02-3659, revised 2006: Пер. с англ. под ред. А.Г.Чучалина. М.: Атмосфера; 2007.

2. Pauwells R.A., Lofdahl C.-G., Postma D. et al. Effect of inhaled formoterol and budesonide on exacerbations of asthma. N. Engl. J. Med. 1997; 337 (20): 1412-1418.

3. Bateman E.D., Boushley H.A., Bousquet J. et al. Can guideline-defined asthma control be achieved? The Gaining Optimal Asthma Control Study. Am. J. Respir. Crit. Care Med. 2004; 170: 836-844.

4. Castle W., Fuller R., Hall J., Palmer J. Serevent nationwide surveillance study:comparison of salmeterol with salbutamol in asthmatic patients who require regular bronchodilator treatment. Br. Med. J. 1993; 306: 1034-1037.

5. Nelson H.S., Weiss S.T., Bleecker E.R. et al. The salmeterol multicenter asthma research trial (SMART): a comparisan of usual pharmacotherapy for asthma ог usual pharmacotherapy plus salmeterol. Chest 2006; 129 (1): 15-26.

6. Barnes $P$. Beta-adrenergic receptors and their regulation. Am. J. Respir. Crit. Care Med. 1995; 152 (3): 838-860.

7. Oppenheimer J., Nelson H.S. Safety of long-acting $\beta$-agonists in asthma: a review. Curr. Opin. Pulm. Med. 2008; 14 (1): 64-69.

8. Bleecker E.R., Postma D.S., Lawrance R.M. et al. Effect of ADRB2 polymorphisms on response to long-acting beta2agonist therapy: a pharmacogenetic analysis of two randomized studies. Lancet 2008; 370 (9605): 2118-2125.

9. Bleecker E.R., Yancey S.W., Baitinger L.A. et al. Salmeterol response is not affected by $\beta_{2}$-adrenergic receptor genotype in subjects with persistent asthma. J. Allergy Clin. Immunol. 2006; 118 (4): 809-816.

10. Sindi A., Todd D.C., Nair P. Antiinflammatory effects of long-acting $\beta_{2}$-agonists in patients with asthma. A systematic review and metaanalysis. Chest 2009; 136 (1): 145-154.

11. Parameswaran K., Fanat A., O'Byrne P.M. Effect of intranasal fluticasone and salmeterol on allergen-induced nasal responces. Allergy 2006; 61 (6): 731-736.

12. Derendorf $H$. Pharmacokinetic and pharmacodynamic properties of inhaled corticosteroids in relation to efficacy and safety. Respir. Med.1997; 91 (suppl. A): 22-28.

13. Adams N., Bestall J., Lasserson T. et al. Inhaled fluticasone versus inhaled beclomethasone or inhaled budesonide for chronic asthma. Cochrane Database Syst. Rev. 2004; 2: CD002310.

14. Irwin R.S., Richardson N.D. Side effects with inhaled corticosteroids. Chest 2006; 130 (1, suppl.): 41S-53S.

15. Shuto H., Nagata M., Terashi Y. et al. Esophageal candidiasis as complication of inhaled steroid therapy. Arerugi 2003; 52: 1053-1064.

16. Spencer C.M., Jarvis B. Salmeterol / fluticasone propionate combination. Drugs I999; 57: 933-940.

17. Lipworth B.J., Jackson C.M. Safety of inhaled and intranasal corticosteroids: lessons for new millennium. Drug Saf. 2000; 23 (1): 11-33.

18. Busse W., Koenig S.M., Oppenheimer J. et al. Steroid sparing effects of fluticasone $100 \mu \mathrm{g}$ and salmeterol $50 \mu \mathrm{g}$ administered twice daily in a single product in patients previously controlled with fluticasone $254 \mu \mathrm{g}$ twice daily. J. Allergy Clin. Immunol. 2003; 111 (1): 57-85.

19. Bailey W., Castro M., Matz J. et al. Asthma exacerbations in African Americans treated for 1 year with combination fluticasone propionate and salmeterol or fluticasone propionate alone. Curr. Med. Res. Opin. 2008; 24 (6): 1669-1682.

20. Ni Chroinin M., Greenstone I.R., Danish A. et al. Long-acting beta2-agonists versus placebo in addition to inhaled corticosteroids in children and adults with chronic asthma. Cochrane Datbase Syst. Rev. 2005; 4: CD005535.

21. Greenstone I.R., Ni Chroinin M.N., Masse V. et al. Combination of inhaled long-acting beta2-agonists and inhaled steroids versus higher dose of inhaled steroids in children and adults with persistent asthma. Cochrane Database Syst. Rev. 2005; 4: CD005533.

22. Ram F.S., Cates C.J. Long-acting beta2-agonists versus anti-leukotrienes as add-on therapy to inhaled corticosteroids for chronic asthma. Cochrane Database Syst. Rev. 2006; 4: CD003137. 


\title{
Чувствовать свободу от астмы
}

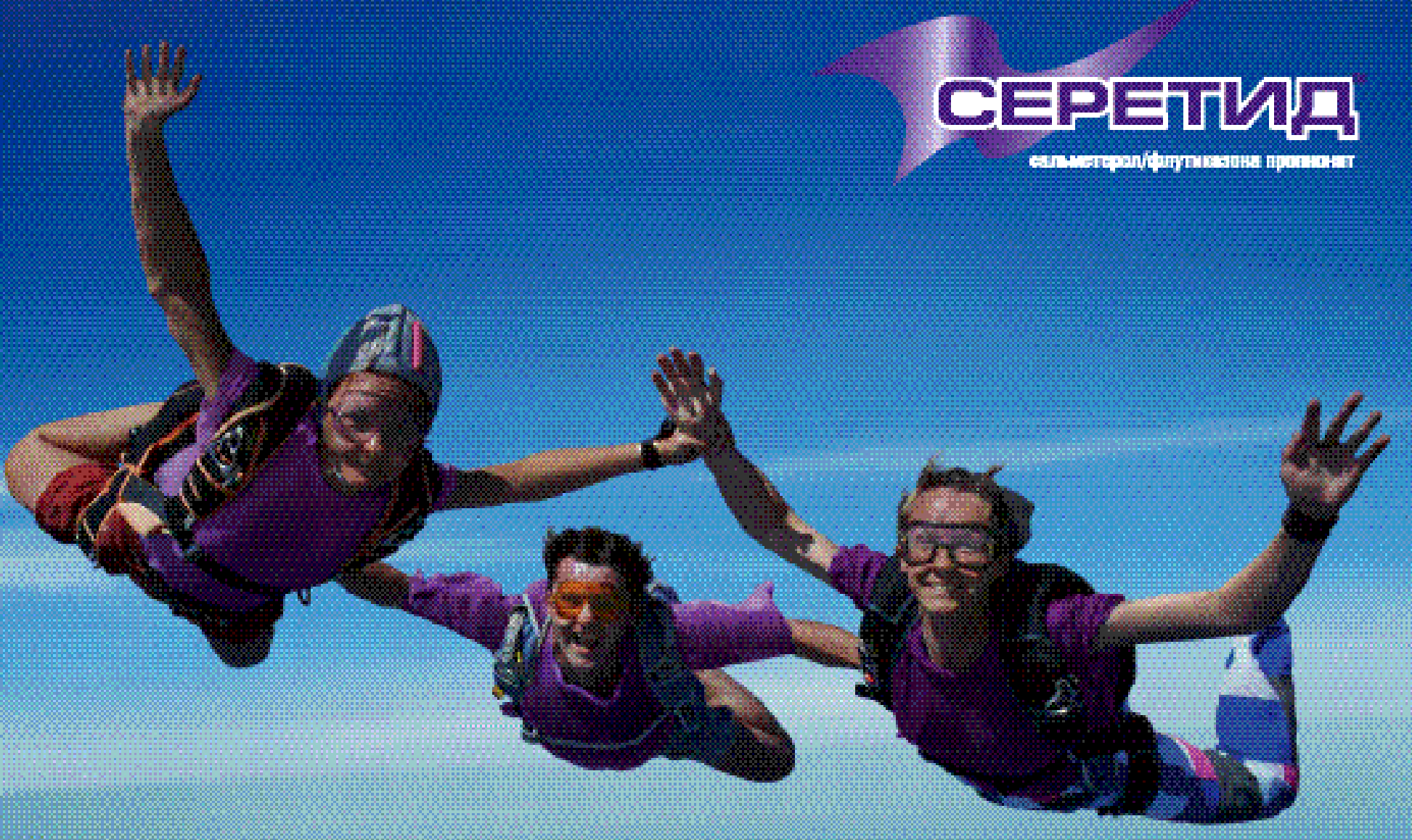

\section{Серетия" - единственная комбинация ИГКСІДДБА, позволяющая ДОСТИЧЬ и ПОДДЕРЖИВАТЬ контроль астмы*:,}

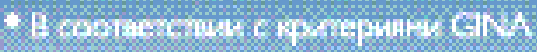

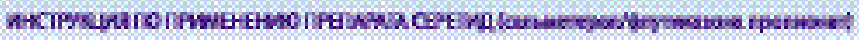

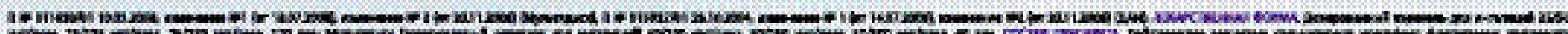

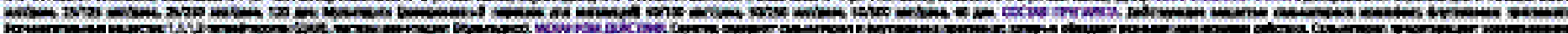

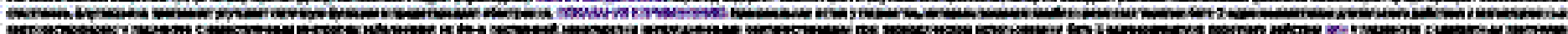

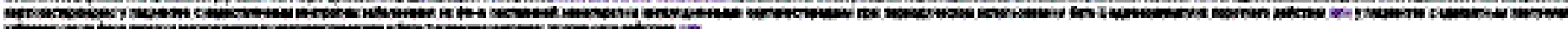

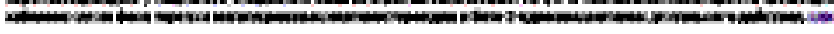

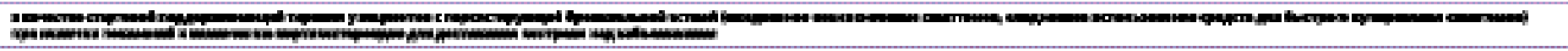

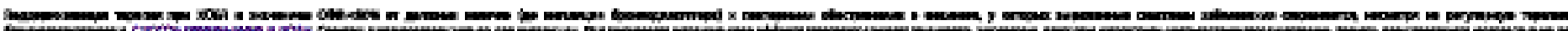

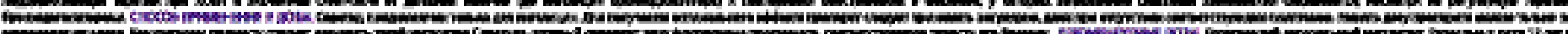

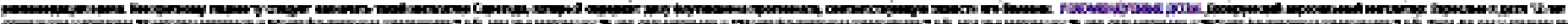

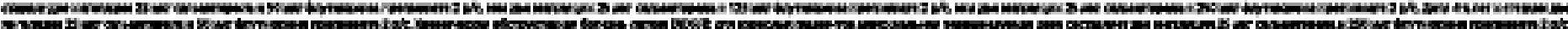

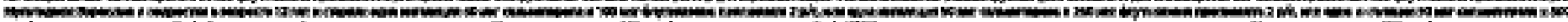

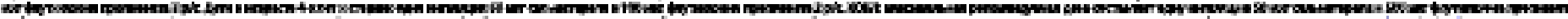

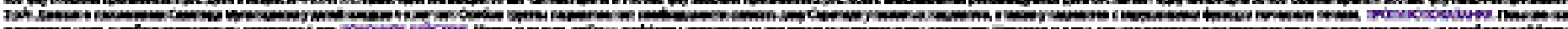
Y

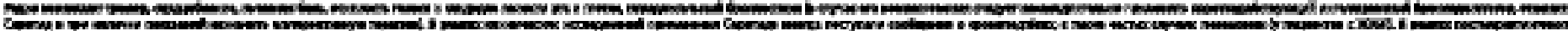

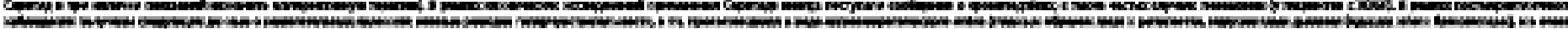

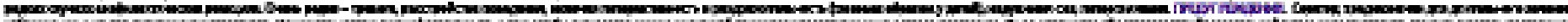
C.

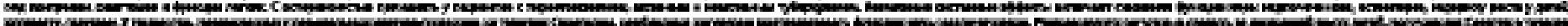
M. mingen

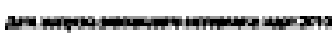

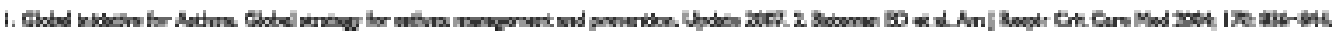

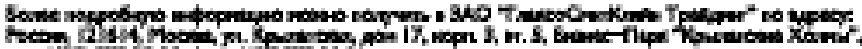

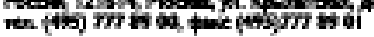


23. Ni Chroinin M., Greenstone I.R., Ducharme F.M. Addition of inhaled long-acting beta2-agonists to inhaled steroids as first line therapy for persistent asthma in steroid-naive adults. Cochrane Database Syst. Rev. 2005; 2: CD005307.

24. Wurthwein G., Render S., Rodhewald P. Lipophility and receptor affinity of glucocorticoids. Pharm Ztg. Wiss. 1992; 5: $2-8$.

25. Barnes N.C., Hallett C., Harris T.A. Clinical experience with fluticasone propionate in asthma: a meta-analysis of efficacy and systemic activity compared with budesonide and beclomethasone dipropionate at half the microgram dose or less. Respir. Med. 1998; 92: 95-104.

\section{Информация об авторах:}

Емельянов Александр Викторович - д. м. н., зав. кафедрой пульмоно логии с курсом аллергологии Санкт-Петербургской медицинской академии последипломного образования; тел.: (812) 301-98-11, доб. 3312; e-mail: emelav@inbox.ru

Сергеева Галина Раисовна - к. м. н., доцент кафедры пульмонологии с курсом аллергологии Санкт-Петербургской медицинской академии последипломного образования; тел.: (812) 301-98-11, доб. 3312; e-mail: sergeevagr@inbox.ru 